\title{
Interferon Beta-1A
}

National Cancer Institute

\section{Source}

National Cancer Institute. Interferon Beta-1A. NCI Thesaurus. Code C1823.

A synthetic version of naturally occurring interferons that have immunomodulatory, antiviral and antiproliferative activities. It may exert antitumor activity by anti-angiogenic and cell differentiation activities. ( $\mathrm{NCl})$ 